\title{
Performance Measurement of SMS and/or Chat Service
}

Sigit Haryadi

Institut Teknologi Bandung

February 2018

Paper DOI10.17605/OSF.IO/H76UC

Citation: Haryadi, S. (2018, March 4). Performance Measurement of SMS and/or Chat Service. Retrieved from osf.io/preprints/inarxiv/h76uc

\section{Abstract}

This paper summarizes my papers and books, which reports on studies concerning the performance measurement of SMS and/or Chat services, particularly on mobile networks. In detail, SMS and/or Chat service quality measurements are grouped into two, the first is a measurement that aims to measure the provider's customer satisfaction, performed by the provider for internal purposes, or to report to the regulator, and the second measurement goal is that the provider and/or by the vendor in relation to the quality assurance provided by the vendor to the provider. In detail, the first type of measurement uses a sampling technique with refer to the subjective method, otherwise, the second type performs aggregate measurements with refer to the Signaling Ladder Diagram of the SMS and/or Chat services.

\section{Types of Quality of Experience and Quality of Service Measurement of SMS and/or Chat Service}

Measurement of SMS and/or Chat service quality is grouped into two, the first is a measurement that aims to measure provider's customer satisfaction and the second measurement goal is that the provider and/or vendor is involved with the quality assurance provided by the vendor to the provider. 


\section{Quality Measurement of SMS and/or Service for Customer Satisfaction}

In relation to the customer satisfaction, SMS and/or Chat service quality measurements are carried out in a sampling of customers of the providers, thus the measured is QoE (Quality of Experience) rather than QoS (Quality of Service). In this type of measurement, the measured parameter is the SMS End-to-End Delivery Time. The Quality of Experience is shown in the form of Mean Opinion Score (MOS), and the size of the MOS value is between 1.0 and 4.5 depending on the quality of the SMS and/or Chat End-to-End Delivery Time subjectively according to customer. In detail, MOS $=1.0$ corresponds to a customer statement that feels absolutely unable to send SMS and/or Chat, so have to repeat send again; instead, MOS = 4.5 is representing a very satisfied customer for the quality of the SMS and/or Chat.

Note: as a benchmark, there are some providers that provide MOS values in the range of 1 and 5 (not from 1 and 4.5).

The subjective measurement technique applies the statistical science and combines it with knowledge of ITU-T Recommendation P.830, 1996, which is a subjective method for quality assessment of broadband band and digital encoding aspects.

The application of statistical science should be accompanied by an in-depth understanding of the customer characteristics of the service provider, where the number of respondents interviewed is generally much more than the amount required for data processing.

For example, we only need data to be processed as many as 100 customers, then we should have 100 respondents who meet all the criteria of the type of customer provider, assume that is that meet the criteria for comparison of female and male customers, e.g. $55 \%$ versus $45 \%$, and also meet the customer age criteria, e.g. $60 \%$ of youth and $40 \%$ of established age, also meet the criteria of income level, e.g. $65 \%$ lower and $35 \%$ middle, and should meeting the criteria of call intensity, e.g. $75 \%$ rarely call and $25 \%$ more than three times a day. As an example of calculation, of all respondents who meet the criteria of the provider's customers, 
$20 \%$ stated that the quality of SMS and/or Chat end to end delivery time s very good, $30 \%$ said well, $25 \%$ said enough, and $15 \%$ said bad and $10 \%$ said the quality was poor. Then MOS $=20 \% * 4.5+30 \% * 4+25 \% * 2.5+15 \% * 2+10 \% * 1=3.125$ which state that the quality is relatively good.

\section{Quality Measurement of the SMS and/or Chat Services in Relation between Provider and Vendor or OTT Provider.}

Measurements of network performance and quality of SMS and/or Chat services in relation to vendors should be done based on the aggregate data, not a sampling, and should refer to the Signaling Ladder Diagram of the SMS and/or Chat services. The problem faced by the provider is almost the vendor's Signaling Ladder Diagram is not $100 \%$ the same as the Signaling Ladder Diagram compiled by International Standard ETSI and 3 GPP. Another problem is related to services provided by over-the-top providers that have no interconnection links with broadband providers, so that providers cannot ask for quality accountability to over-the-top providers.

Some important parameters on this type of measurement are:

1) SMS and/or Chat Service Non-Accessibility

2) SMS and/or Chat end-to-end delivery time

3) SMS and/or Chat SMS Completion Failure Ratio

SMS (Short Message Service) and/or Chat is a specialized telecommunications service, where the short-message limited to a maximum of 160 characters, and if sent over 160 characters is referred to as long SMS and/or Chat.

SMS in the past is served by a server called SMSC (SMS Center), but in an era of over-the-top service, a chat is served by the over-the-top servers.

There is a complex problem, when measuring the performance of SMS using a counter and timer of the provider for the information related to the success or failure of the signaling and the period required for the signaling process does not exist in a single network element, then 
the providers which are not able to integrate information on the counters and timers, will be able to measure the performance of SMS and/or chat using a "drive-test" only, so the measurement data are only samples, and can not be aggregate data.

\subsection{SMS and/or Chat Service Non-Accessibility}

The probability that MO (Mobile Originated = SMS and/or chat sender) cannot access the SMS and/or Chat service, while at the same time there is a display of the network indicators in Mobile Equipment, which shows Network-availability, is in good condition.

Beginning of the SMS and/or Chat: Push send button by MO to initiate sending an SMS and/or Chat, the "Access request" signal is sent by the MO to the SMSC (SMS-Centre) or Over-thetop server.

The end of a successful process of accessibility is the MO receives the acknowledgment from the SMSC or over-the-top server, in the form of the delivery report.

Abstract Equation of SMS and/or Chat Service Non-Accessibility:

$$
\text { SMS or Chat Service Non }- \text { Accessibility (\%) }=\frac{\text { Unsuccessful SMS or Chat attempts }}{\text { all SMS or Chat attempts }} \times 100
$$

\subsection{SMS and/or Chat End-to-End Delivery Time}

End-to-end delivery time is the duration is calculated from the sending-party start sending SMS up to the receiving-party has received SMS and/or Chat.

Beginning of the SMS and/or Chat: Push send button by MO to initiate sending an SMS and/or Chat, the "Access request" signal is sent by the MO to the SMSC (SMS-Centre) or Over-thetop server.

The end of a successful process of SMS and/or Chat end-to-end delivery time: The Short or Long Message is received by MT (Mobile Terminating) party's, indicated the presence of Message Transfer" is received in the sender gadget and recorded on counters and timers in the SMSC and/or in the over-the-top servers. 
Abstract Equation of SMS and/or Chat end-to-End Delivery Time:

$S M S$ or Chat end - to - end Delivery Time $=t_{M T}$ receive SMS or Chat $-t_{M O}$ send SMS or Chat

\subsection{SMS and/or Chat Completion Failure Ratio}

SMS and/or Chat completion failure ratio is the Ratio between SMS and/or Chat not received in the gadget of MT and SMS send from the MO; excluding duplicate received and corrupted SMS and/or Chat. Where a corrupted SMS and/or Chat is a SMS and/or Chat which has at least one bit error.

Beginning of the SMS and/or Chat: Push send button by MO to initiate sending an SMS and/or Chat, the "Access request" signal is sent by the MO to the SMSC (SMS-Centre) or Over-thetop server.

The end of a successful process of SMS and/or chat was completed: The Short or Long Message is received by the MT (Mobile Terminating) party's, indicated with the presence of "Message Transfer" is received in the gadget of the sender and recorded on counters and timers in the SMSC or over-the-top servers.

Abstract Equation of the Completion Failure Ratio:

SMS or Chat Completion Failure ratio $=$

unsuccessful received SMS or Chat-duplicated received SMS or Chat-Corrupted SMS or Chat all sent SMS or Chat

\section{Signaling Ladder Diagram}

a) Signaling ladder diagrams of SMS in the past are much more complicated than Chat service being served by the over-the-top servers, because in the past a poorly performing SMS should be searched for which network elements is work poorly, for immediate repair, on the other hands the over-the-top providers do not care about the network performance, so the designed signaling ladder diagram is much simpler.

b) Signaling Ladder Diagram of the SMSC is compiled with reference to the ETSI standard and others, in chapter 4 is given a table describing the signaling ladder diagram of SMS occurring in 3G cellular networks. 
c) Signaling ladder diagram of the Chat service provided by over-the-top providers is kept

by the provider, so even though I can estimate it, I cannot tell it here.

Table 1. Signaling Ladder Diagram of the Standard 3G Cellular Network

\begin{tabular}{|c|c|c|c|c|}
\hline $\begin{array}{l}\text { Trigger } \\
\text { Point }\end{array}$ & $\begin{array}{l}\text { Logical } \\
\text { Channel }\end{array}$ & Signal Name & $\begin{array}{l}\text { Outgoing } \\
\text { Network } \\
\text { Element }\end{array}$ & $\begin{array}{l}\text { Incoming } \\
\text { Network } \\
\text { Element }\end{array}$ \\
\hline \multirow[t]{34}{*}{$\begin{array}{l}\text { START: } \\
\text { Sender press } \\
\text { the Send } \\
\text { Button }\end{array}$} & $\mathrm{DCCH}$ & Initial DT (CM Service Request) & MO & RNC1 \\
\hline & & $\begin{array}{l}\text { SCCP Connection RQ (CM Service } \\
\text { Request) }\end{array}$ & RNC1 & MSC1/VLR1 \\
\hline & & SCCP Connection Confirm & MSC1/VLR1 & $\mathrm{RNC1}$ \\
\hline & & Common ID & $\mathrm{RNC1}$ & MSC1/VLR1 \\
\hline & & Location Reporting Control & MSC1/VLR1 & $\mathrm{RNC1}$ \\
\hline & & Security Mode Command & MSC1/VLR1 & $\mathrm{RNC1}$ \\
\hline & & Security Mode Command & RNC1 & MO \\
\hline & $\mathrm{DCCH}$ & Security Mode Complete & $\mathrm{MO}$ & $\mathrm{RNC1}$ \\
\hline & & Security Mode Complete & $\mathrm{RNC1}$ & MSC1/VLR1 \\
\hline & & DT (Identity Request) (IMEI) & $\mathrm{RNC1}$ & MSC1/VLR1 \\
\hline & & DLDT (Identity Request) (IMEI) & RNC1 & MO \\
\hline & & ULDT (Identity Response) (IMEI) & MO & RNC1 \\
\hline & & DT (Identity Response) (IMEI) & RNC1 & MSC1/VLR1 \\
\hline & & Direct Transfer SM & MSC2/VLR2 & $\mathrm{RNC2}$ \\
\hline & DCCH & Uplink Direct Transfer/CP-DATA & MO & RNC1 \\
\hline & & Direct Transfer & $\mathrm{RNC1}$ & MSC1/VLR1 \\
\hline & & Message Transfer & MSC1/VLR1 & SMSC \\
\hline & & Message Transfer & SMSC & MSC1/VLR1 \\
\hline & & SendRoutingInfo-ForShortMsg & SMSC & HLR \\
\hline & & SendRoutingInfo-ForShortMsg & HLR & SMSC \\
\hline & & forwardShortMessage & SMSC & MSC2/VLR2 \\
\hline & & Direct Transfer & MSC1/VLR1 & $\mathrm{RNC1}$ \\
\hline & & DLDT/CP-ACK & $\mathrm{RNC1}$ & MO \\
\hline & & Paging & MSC2/VLR2 & RNC2 \\
\hline & & Paging Type1 & $\mathrm{RNC2}$ & Node B2 \\
\hline & $\mathrm{RACH}: \mathrm{CCCH}$ & RRC Connection Request & MT & $\mathrm{RNC2}$ \\
\hline & & Radio Link Setup Request & Node B2 & RNC2 \\
\hline & & Radio Link Setup Request & RNC2 & Node B2 \\
\hline & & Radio Link Setup Response & Node B2 & $\mathrm{RNC2}$ \\
\hline & & Establish Request (AAL2) & RNC2 & Node B2 \\
\hline & & Establish Confirm (AAL2) & Node B2 & RNC2 \\
\hline & & Downlink Synchronization & $\mathrm{RNC2}$ & Node B2 \\
\hline & & Uplink Synchronization & Node B2 & RNC2 \\
\hline & FACH:CCCH & RRC Connection Setup & $\mathrm{RNC2}$ & MT \\
\hline
\end{tabular}




\begin{tabular}{|c|c|c|c|c|}
\hline & $\mathrm{DCCH}$ & INSYNCH IND & MT & Node B2 \\
\hline & & Radio Link Restore Indication & Node B2 & $\mathrm{RNC2}$ \\
\hline & $\mathrm{DCCH}$ & RRC Connection Setup Complete & MT & $\mathrm{RNC2}$ \\
\hline & $\mathrm{DCCH}$ & Paging Response & MT & $\mathrm{RNC2}$ \\
\hline & & SCCP Connection Request & $\mathrm{RNC2}$ & MSC2/VLR2 \\
\hline & & $\begin{array}{l}\text { UE Connection Establish (Paging } \\
\text { Response) }\end{array}$ & $\mathrm{RNC} 2$ & MSC2/VLR2 \\
\hline & & SCCP Connection Confirm & MSC2/VLR2 & $\mathrm{RNC2}$ \\
\hline & & Common ID & $\mathrm{RNC2}$ & MSC2/VLR2 \\
\hline & & Location Reporting Control & MSC2/VLR2 & $\mathrm{RNC2}$ \\
\hline & & Security Mode Command & MSC2/VLR2 & $\mathrm{RNC2}$ \\
\hline & $\mathrm{DCCH}$ & Security Mode Command & $\mathrm{RNC2}$ & MT \\
\hline & $\mathrm{DCCH}$ & Security Mode Complete & MT & $\mathrm{RNC2}$ \\
\hline & & Security Mode Complete & $\mathrm{RNC2}$ & MSC2/VLR2 \\
\hline & & DT (Identity Request) (IMEI) & MSC2/VLR2 & $\mathrm{RNC2}$ \\
\hline & $\mathrm{DCCH}$ & DLDT (Identity Request) (IMEI) & $\mathrm{RNC2}$ & MT \\
\hline & $\mathrm{DCCH}$ & ULDT (Identity Response) (IMEI) & MT & $\mathrm{RNC2}$ \\
\hline & & DT (Identity Response) (IMEI) & $\mathrm{RNC2}$ & MSC2/VLR2 \\
\hline & & Direct Transfer & MSC2/VLR2 & $\mathrm{RNC2}$ \\
\hline \multirow{6}{*}{$\begin{array}{l}\text { STOP of the } \\
\text { measurement } \\
\text { of (1) End- } \\
\text { to-end } \\
\text { Delivery } \\
\text { Time, and } \\
\text { (2) Failure } \\
\text { Ratio }\end{array}$} & $\mathrm{DCCH}$ & Downlink Direct Transfer/ CP-Data & $\mathrm{RNC2}$ & MT \\
\hline & $\mathrm{DCCH}$ & Uplink Direct Transfer/CP-ACK & MT & $\mathrm{RNC2}$ \\
\hline & & Direct Transfer & $\mathrm{RNC2}$ & MSC2/VLR2 \\
\hline & & Delivery Report & MSC2/VLR2 & SMSC \\
\hline & & Delivery Report & SMSC & MSC1/VLR1 \\
\hline & & Direct Transfer & MSC1/VLR1 & $\mathrm{RNC1}$ \\
\hline $\begin{array}{l}\text { STOP of the } \\
\text { measurement } \\
\text { of Service } \\
\text { Accessibility. }\end{array}$ & $\mathrm{DCCH}$ & Downlink Direct Transfer/ CP-Data & $\mathrm{RNC} 1$ & MO \\
\hline
\end{tabular}

In principle, the measurement process of "SMS end-to-end delivery time" and the measurement process "SMS Completion Failure ratio" is equal, but the difference is, the measurement of "delivery time" refers to the timers, whiles the measurement of "success or failure" is referring to the counters.

\section{Note:}

To the readers of this short paper, if you want to deepen the knowledge of this field, welcome to read the papers and books in the references. 


\section{References:}

[1] Haryadi, S. (2018, February 26). Measurement of Cellular Network's Availability and Reliability based on the Signaling Ladder Diagram. Retrieved from osf.io/preprints/inarxiv/hwvm8

[2] European Telecommunications Standards Institute. (2011). Speech and multimedia Transmission Quality (STQ), QoS aspects for popular services in mobile networks; Part 1. Assessment of Quality of Service, ETSI TS 102 250-1 V2.2.1

[3] European Telecommunications Standards Institute. (2011). ETSI Standard TS 102 250-2 v2.2.1: Speech and multimedia Transmission Quality (STQ); QoS aspects for popular services in mobile networks; Part 2: Definition of Quality of Service parameters and their computation.

[4] ETSI. (2008). ETSI Standard EG 202-057 V1.3.1: Speech Processing, Transmission and Quality Aspects (STQ).

[5] ITU-T. (2014). ITU-T Recommendation G.107: The E-Model, a computational model for use in transmission planning.

[6] Sigit Haryadi. (2013). Telecommunication Traffic: Technical and Business Consideration. Lantip Safari Media, Bandung, Indonesia. ISBN: 978-602-18578-5-4.

[7] Sigit Haryadi. (2013). Telecommunication Service and Experience Quality. Lantip Safari Media, Bandung, Indonesia. ISBN: 978-602-18578-6-1.

[8] Haryadi, Sigit; Limampauw, Ivantius. (2012). QoS Measurement of Telephony Services In 3G Networks Using Aggregation Method. Conference Proceeding of TSSA 2012. Denpasar, Indonesia.

[9] Haryadi, Sigit; Nusantara, Sandy. (2012). QoS Measurement of Web Browsing Services In 3G Networks Using Aggregation Method. Conference Proceeding of TSSA 2012. Denpasar, Indonesia.

[10] Haryadi, Sigit; Pramudita, Arnold. (2012). QoS Measurement of Video Streaming Services in a 3G Networks Using Aggregation Method. Conference Proceeding of TSSA 2012. Denpasar, Indonesia.

[11] Haryadi, Sigit; Andina, Raisha. (2012). QoS Measurement of File Transfer Protocol Services In 3 G Networks Using Aggregation Method. Denpasar, Indonesia. 2012.

[12] Haryadi, S. (2017, November). Probabilitas Statistik Untuk Insinyur. Researchgate. DOI10.13140/RG.2.2.14304.58885

[13] Sigit Haryadi. (2017). the Non-Intercept Linear Regression Method. Researchgate. DOI10.13140/RG.2.2.18721.71522

[14] [37] Sigit Haryadi. (2018, February). Applied Statistics for Assessment of the Regulation and Policy: case study in Telecommunication Industry.

DOI10.13140/RG.2.2.15774.02884

[15] Haryadi, S. (2018, February 7). Statistik Terapan: Pengujian Regulasi \& Kebijakan Telekomunikasi. Retrieved from osf.io/3pkfw

[16] Haryadi, S. (2018, January 25). Chapter 1. The Concept of Telecommunication Network Performance and Quality of Service. Retrieved from osf.io/mukqb

[17] Haryadi, S. (2018, January 26). Chapter 2 of Network Performance and Quality of Service: Determination of Key Performance Indicator (KPI). Retrieved from osf.io/preprints/inarxiv/6gtnd

[18] Haryadi, S. (2018, January 26). Chapter 3 of Network Performance and Quality of Service: Technical Measurement of a Mobile Network Performance and Quality of Service. Retrieved from osf.io/q4wsz 
[19] Haryadi, S. (2018, January 30). Basic Calculation of the Network's Availability and Reliability (Chapter 4 of Network Performance and Quality of Service). Retrieved from osf.io/preprints/inarxiv/z5mwq

[20] Haryadi, S. (2018, February 26). Measurement of Cellular Network's Availability and Reliability based on the Signaling Ladder Diagram. Retrieved from osf.io/preprints/inarxiv/hwvm8

[21] Haryadi, S. (2018, February 27). Performance Measurement of Telephone Network and Service. Retrieved from osf.io/preprints/inarxiv/5c7qa

[22] Sigit Haryadi. (2017). Haryadi Index and Its Applications in Science of Law, Sociology, Economics, Statistics, and Telecommunications. Penerbit Elex Media Komputindo. Jakarta. ISBN 978-602-02-9895-5.

[23] Sigit Haryadi. (2017). Indeks Haryadi dan Penerapan di Ilmu Hukum, Sosiologi, Ekonomi, Statistik, dan Telekomunikasi. Penerbit Elex Media Komputindo, Jakarta. ISBN 978-602-02-9896-2

[24] Sigit Haryadi. (2016). Haryadi Index for Competition, Equality and Correlation Evaluation. Penerbit Lantip Safari Media, Bandung, Indonesia. ISBN 978-602-73231-3-2

[25] Sigit Haryadi. (2016). Haryadi Index untuk Evaluasi Kompetisi, Kesetaraan dan Korelasi. Penerbit Lantip Safari Media, Bandung, Indonesia. ISBN 978-60273231-3-1

[26] Sigit Haryadi. (2017). Calculation of the Mobile Communication Competition using Haryadi Index. DOI10.13140/RG.2.2.15634.25280

[27] [97] Sigit Haryadi. (2017). the Equality Correlation Method. Researchgate. DOI10.13140/RG.2.2.10443.80169.

[28] Muhammad Rizky Hikmatullah; Sigit Haryadi. (2017). Perceptual evaluation of speech quality over the top call service. 3rd International Conference on Wireless and Telematics (ICWT), Indonesia.

[29] Rizna Nofitasari; Sigit Haryadi. (2017). Self-healing mechanism with RSRP measurement in LTE network. 3rd International Conference on Wireless and Telematics (ICWT), Indonesia.

[30] Fidyatun Nisa; Sigit Haryadi. (2016). Simulation of the fault management with Self Healing mechanism (case study: LTE Network in Banda Aceh Area). 10th International Conference on Telecommunication Systems Services and Applications (TSSA), Indonesia.

[31] Suci Ramadona; Sigit Haryadi; Dyah Rakhma Aryanti. (2015). Over the top call service key performance indicator. 1st International Conference on Wireless and Telematics (ICWT), Indonesia.

[32] Maya Rahayu; Sigit Haryadi; Dyah Rakhma Aryanti. (2015). Over the Top chat service key performance indicator. 1st International Conference on Wireless and Telematics (ICWT), Indonesia.

[33] Sigit Haryadi. (2016). Telecommunication Quality of Service Concept.

Research gate. Available online at https://www.researchgate.net/publication/313101013_Telecommunication_Quality_of Service_Concept

[34] Sigit Haryadi. (2016). Grade of Service \& Quality of Service Concept and Analysis. Researchgate. Available online at https://www.researchgate.net/publication/313101070_Grade_of_Service_Quality_of Service_Concept_and_Analysis

[35] Sigit Haryadi. (2016). Performance Indicator of Telecommunication Service. Researchgate. Available online at 
https://www.researchgate.net/publication/313101244_Performance_Indicator_of_Tele communication_Service. 